\title{
Trastorno por estrés agudo. Presentación de un caso
}

\author{
Acute stress disorder. Case report
}

\section{Resumen}

El trastorno por estrés agudo puede ser secundario a una lesión grave o una amenaza a la integridad física. Ante este tipo de situación, el individuo responde con una serie de reacciones cognitivas, conductuales, emocionales y físicas todas ellas orquestadas por un órgano rector: el cerebro. Se presenta el caso de una paciente con un trastorno por estrés agudo que aparece tras ser agredida en su puesto laboral. Se trata de una mujer de 55 años, con antecedentes de un adecuado desempeño laboral, que después del evento traumático comienza a presentar cambios conductuales evidenciados por irritabilidad, miedo, ansiedad, nerviosismo y sobresaltos. No quiere salir sola a la calle, aqueja malestar al recordar el evento traumático y pérdida de su estabilidad emocional y laboral. Cuando se realiza la evaluación, la paciente se encontraba bajo tratamiento con antidepresivos y ansiolíticos. Se recomienda integrar estudios electrofisiológicos, psicofisiológicos y métodos de evaluación clinimétrica como complemento en el diagnóstico de esta entidad.

Palabras clave: Estrés agudo. Respuesta simpática de la piel. EEG.

\section{Abstract}

Acute stress disorder may be the secondary to a serious injury or a threat to physical integrity. Given this situation, the individual responds with a series of cognitive, behavioral, emotional and physical reactions all orchestrated by a governing body: the brain. A case of a patient with acute stress disorder, which appears after being attacked in her job place, is presented. A 55-year old woman, with antecedents of adequate job performance, begins to show behavioral changes evidenced by irritability, fear, anxiety, nervousness and jumpiness after the traumatic event. She does not want to go alone into the street, explains malaise when remembering the traumatic event and loss of emotional and labour stability. At the time when the assessment is made, the patient was being treated with antidepressants and anxiolytics. It is recommended to integrate electrophysiological, psychophysiological and methods of clinometric evaluation as complements for the diagnosis of this entity.

Key words: Acute stress. Sympathetic answer of the skin. EEG.

\section{Introducción}

El trastorno por estrés agudo es un cuadro de carácter agudo que aparece como consecuencia de la exposición a un evento traumático. Las manifestaciones clínicas aparecen dentro del plazo de una hora posterior al psico-trauma. Existen criterios estandarizados que aparecen recogidos en el manual estadístico de enfermedades mentales ${ }^{1}$ y permiten un diagnóstico adecuado de esta entidad (Tabla 1 ).
En el trastorno por estrés agudo un elemento central es el trauma psíquico, es decir, el impacto emocional de un determinado suceso capaz de provocar una serie de manifestaciones físicas y psicológicas ${ }^{2}$.

El acontecimiento traumático ha sido definido por la Asociación Psiquiátrica Americana como aquella situación psicológicamente estresante que sobrepasa el repertorio de las experiencias habituales de la vida (como puede ser un duelo simple, una enfermedad

\author{
A. Calzada Reyes ${ }^{1}$ \\ YC. Oliveros Delgado² \\ Y. Acosta Imas ${ }^{3}$
}

${ }^{1}$ Especialista en $1^{\circ}$ y $2^{\circ}$ Grado en Fisiología Normal y Patológica (con dedicación a la Neurofisiología Clínica). Profesora Auxiliar. Instituto de Medicina Legal. Habana. Cuba. ${ }^{2}$ Especialista en $1^{\circ}$ Grado en Medicina Legal. Instituto de Medicina Legal. Habana. Cuba. ${ }^{3}$ Master en Neurociencias. Centro de Neurociencias de Cuba. Habana. Cuba.

Correspondencia: Ana Calzada Reyes Servicio de Neurofisiología Clínica.

Instituto de Medicina Legal Av. Independencia y Hernán Cortés. Plaza, 10600 Habana (Cuba)

E-mail:

anacalz@infomed.sld.cu

Fecha de recepción: 17.MAR.2012

Fecha de aceptación: 30.MAR.2012 
crónica, una pérdida económica o un conflicto sentimental), que afectará prácticamente a todas las personas y que provocará un intenso miedo, terror y desesperanza, con una seria amenaza para la vida o la integridad física personal o de un tercero².

Se trata de un suceso de características particulares, identificable (situaciones de combate, explosiones, catástrofes, accidentes, maltrato, abuso o cualquier otra situación de violencia física o psíquica), que se produce en forma sorpresiva, inexplicable y brutal, provocando súbitamente una amenaza para la integridad, para sí o para terceros, que se encuentra fuera de las experiencias cotidianas del sujeto y sobre la cual no se puede ejercer ningún control ${ }^{3}$.
Ante una situación de estrés, existe un compromiso de todo el organismo; no obstante el cerebro es el órgano central de la respuesta fisiológica, psicológica y del comportamiento ante el estrés ${ }^{4}$. El uso de escalas y la aplicación de técnicas electrofisiológicas y psicofisiológicas resultan de gran valor como métodos complementarios en el diagnóstico de esta entidad.

En este artículo se presenta el caso de una paciente diagnosticada de trastorno por estrés agudo como consecuencia de haber sufrido una situación traumática intensa en su puesto de trabajo. Se presenta, además, su evaluación clínica y las técnicas que evalúan el funcionamiento del sistema nervioso central y periférico.
Tabla 1.

Criterios diagnósticos de trastorno por estrés agudo del DSM-IV-TR

\section{A. La persona ha estado expuesta a un suceso traumático en el que experimentó las dos situaciones siguientes:}

1. La persona experimentó, presenció o enfrentó un acontecimiento o sucesos, que implicaron muerte real o amenaza de muerte, o lesión grave, o una amenaza a su integridad física o la de otros.

2. La respuesta de la persona fue miedo intenso, indefensión u horror.

B. Mientras experimenta o tras experimentar al suceso traumático, el individuo presenta tres (o más) de los siguientes síntomas disociativos:

1. sensación subjetiva de embotamiento, desapego o ausencia de respuesta emocional

2. disminución de la conciencia de su entorno (por ej., estar aturdido)

3. desrealización

4. despersonalización

5. amnesia disociativa (incapacidad de recordar un aspecto importante del trauma).

C. Se vuelve a experimentar persistentemente el suceso traumático en uno (o más) de los siguientes modos: imágenes, pensamientos, sueños, ilusiones, episodios de imágenes retrospectivas recurrentes, o una sensación de revivir la experiencia; o malestar al exponerse a recordatorios del suceso traumático.

D. Notoria evitación de estímulos que despiertan recuerdos del trauma (por ej., pensamientos, sentimientos, conversaciones, actividades, lugares, gente).

E. Notorios síntomas de ansiedad o mayor excitación (por ej., dificultad para dormir, irritabilidad, escasa concentración, estado de hiperalerta, respuesta de alarma exagerada, desasosiego motor).

F. La alteración causa malestar o deterioro clínicamente significativo del desempeño social, ocupacional o en otras esferas importantes, o altera la capacidad del individuo para realizar alguna tarea necesaria, como obtener necesaria o movilizar recursos personales contándole a sus familiares la experiencia traumática.

G. La alteración persiste un mínimo de 2 días y un máximo de 4 semanas, y sobreviene dentro de las 4 semanas del episodio traumático.

H. La alteración no se debe a los efectos fisiológicos directos de una sustancia (por ej., una droga de abuso, una medicación), ni a una enfermedad médica general, y no se explica mejor por un trastorno psicótico breve, ni es meramente una exacerbación de un trastorno preexistente del Eje I o el Eje II. 


\section{Presentación del caso}

Se trata de una paciente femenina de 55 años, con antecedentes de hipotiroidismo, y con un adecuado desempeño laboral. Mientras realizaba su trabajo fue sorpresivamente agredida por un individuo quien le ocasionó un traumatismo en región frontal izquierda con un objeto romo. La paciente describe que tuvo la sensación de haber recibido un disparo en la cabeza, tras lo que perdió el conocimiento por breve tiempo y fue atendida en el hospital más próximo a su área de trabajo donde recibió tratamiento médico y se suturó la herida en la zona del trauma. Se le realizó TAC no detectándose alteraciones craneoencefálicas.

Fue remitida a nuestra institución 25 días después del suceso con el objetivo de realizar una evaluación forense del daño corporal sufrido. El médico responsable solicitó una evaluación por parte del Laboratorio de Neurofisiología Clínica donde se realizó una entrevista clínica a la paciente y se aplicó el cuestionario de experiencias traumáticas ${ }^{5}$. Se trata de un instrumento sencillo utilizado para el cribado de pacientes con trastorno por estrés postraumático que consta de tres partes diferenciadas: a) listado de experiencias traumáticas (18 ítems que investigan la existencia o no de experiencias traumáticas a lo largo de la vida y en caso afirmativo la edad a que sucedió y la duración), b) acontecimiento traumático que más preocupa en el momento actual con 9 ítems que investigan el acontecimiento estresante según los criterios diagnósticos del apartado A del DSM-IV y c) listado de síntomas que consta de 18 ítems que exploran los criterios B-D del DSM-IV. La respuesta es dicotómica (SÍ-NO) y el marco temporal cualquier momento tras el acontecimiento traumático. Este apartado investiga mediante dos ítems adicionales si ha recibido asistencia sanitaria previamente por este motivo (estos dos últimos no se puntúan). Los únicos ítems que se puntúan son los 18 iniciales del listado de síntomas, 1 punto cada respuesta afirmativa y 0 cada negativa. La puntuación total es la suma de la de los 18 ítems.

Se registró un EEG en condiciones basales en estado de vigilia utilizando el equipo Medicid $V$ y el programa Track Walker (Neuronic, SA CUBA). Se registraron 3 minutos con los ojos cerrados, 2 minutos con los ojos abiertos, 3 minutos durante la hiperventilación y 2 minutos de recuperación y se evaluó la respuesta simpática de la piel, utilizando un diseño experimental conformado a partir de imágenes estandarizadas del Sistema Internacional de Imágenes Afectivas (IAPS; Center for the Study of Emotion and Attention-NIMH, 1999) ${ }^{6}$ que constituye un nuevo método para el estudio experimental de las emociones. El IAPS consiste en un conjunto estandarizado de imágenes en color con capacidad para evocar emociones y cuyos contenidos recorren un amplio abanico de categorías; además, facilita enormemente las tareas de selección y control de los estímulos. Cada imagen del IAPS posee un valor que ha sido normalizado en las dimensiones bipolares de valencia afectiva (con un rango que va desde lo agradable a lo desagradable) y el arousal o activación (cuyo rango oscila entre la excitación y la calma).

Se seleccionaron 6 de ellas con valencia desagradable que mostraban situaciones que representaban peligro para la vida de una persona y 16 neutras y se diseñó el experimento en el programa Mindtracer (Neuronic SA, Cuba). Cada estímulo tenía una duración de 2000 milisegundos y el intervalo inter-estímulo fue de 200.000 milisegundos. El registro se realizó con el equipo BioDerm Modelo 2701 y dos electrodos que se colocaron en la falange media de los dedos índice y medio de la mano dominante.

\section{Resultados}

En la entrevista clínica se destaca la siguiente sintomatología expresada por la paciente: nerviosismo, sobresaltos, ansiedad, no quiere salir sola a la calle, teme porque la persona que la agredió le vuelva hacer lo mismo, trastornos del sueño, malestar al recordar el suceso traumático y pérdida de su estabilidad emocional y laboral. Irritabilidad, escasa concentración, estado de hiperalerta. Teme que la situación de inestabilidad nerviosa persista y no pueda volver ser la misma persona que era antes del suceso. En el momento que fue valorada se encontraba bajo tratamiento con ansiolíticos y antidepresivos.

Cuestionario de experiencia traumática: 17 puntos en la sintomatología de 18 posibles, hace referencia a que el acontecimiento que más le ha afectado es el ocurrido en su centro de trabajo, ya que como consecuencia del mismo ha perdido toda su estabilidad emocional y laboral.

EEG: el análisis visual reveló signos muy ligeros de irritación cortical fronto-temporal izquierdos. No fue posible la realización de análisis cuantitativo porque existían abundantes artefactos fisiológicos en el registro debido a que la paciente se encontraba muy tensa. 
Figura 1. Resultados de la evaluación de la respuesta simpática de la piel. 1 representa la respuesta obtenida ante estímulos neutros y 2 ante estímulos desagradables. En el eje y se refleja el valor de la amplitud de la respuesta expresada en microsiemens.

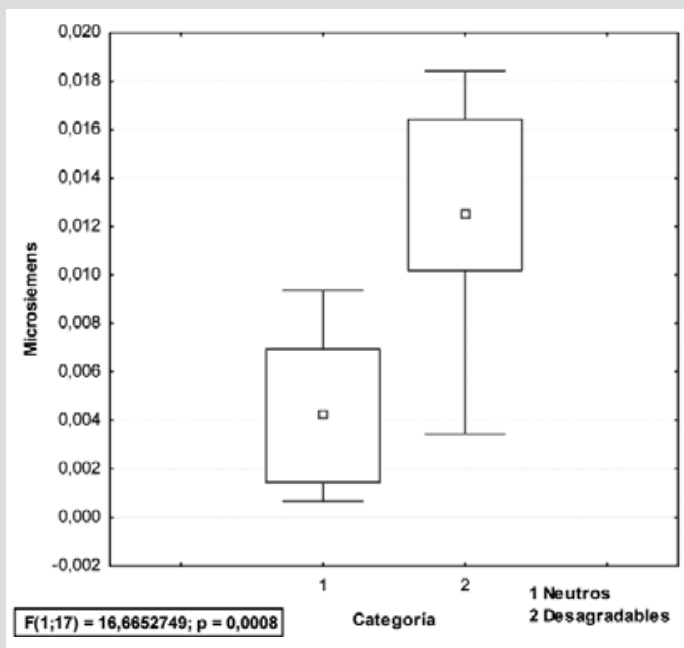

Respuesta Simpática de la piel: incremento estadísticamente significativo de la respuesta ante fotografías con imágenes de valencia desagradables con relación a imágenes neutras (Figura 1 ).

\section{Discusión}

El trastorno por estrés agudo es un diagnóstico psiquiátrico frecuentemente encontrado en sujetos que han sufrido alguna situación traumática grave, ya sea como víctimas o incluso en ocasiones sólo como espectadores. EI DSM-IVR establece en sus criterios el límite de cuatro semanas para diferenciar el trastorno por estrés agudo del trastorno de estrés post-traumático ${ }^{1}$.

Desde el punto de vista clínico ambas entidades tienen en común el mismo perfil en cuanto a la sintomatología, con síntomas invasores (como imágenes, pensamientos o pesadillas relacionadas con el hecho traumático), síntomas de evitación (de lugares, personas, conversaciones o medios de información) y síntomas de hiperalerta (como insomnio, irritabilidad fácil o respuesta exagerada a estímulos sensoriales). Además de los síntomas mencionados en el trastorno por estrés agudo aparecen fenómenos como la amnesia disociativa, la despersonalización y la desrealización ${ }^{1}$.

Los instrumentos de ayuda diagnóstica están diseñados para facilitar al clínico el juicio diagnóstico. En los casos de pacientes con trastorno por estrés agudo, por la posibilidad de evolucionar a un trastorno de estrés postraumático, resulta conveniente reconocer el tipo de estresor extremo que lo ocasionó, el impacto del mismo, la sintomatología, así como la duración de estos síntomas. De ahí que resulta conveniente incluir dentro de la evaluación de cualquier paciente en el que se sospeche o se diagnostique esta entidad instrumentos de screening, como el utilizado en la paciente, objeto de descripción en este trabajo.

En concreto, en esta paciente se empleó el cuestionario de experiencias traumáticas ${ }^{5}$, instrumento autoaplicado que reveló una puntuación elevada, 17 de 18 puntos posibles. Este hallazgo sugiere la necesidad de un seguimiento evolutivo y un adecuado tratamiento a la paciente, con el objetivo de inhibir el desarrollo de un trastorno crónico provocado por el agente estresante. Los pacientes con un trastorno por estrés agudo pueden evolucionar favorablemente y responder adecuadamente a las medidas terapéuticas aplicadas, cuando su diagnóstico y tratamiento es oportuno².

Un hallazgo importante en la paciente estudiada fue la presencia de actividad paroxística en regiones fronto-temporales izquierdas. Se ha postulado que cuando el efecto de una situación traumática se mantiene durante cierto tiempo causa una iniciación subsecuente del denominado fenómeno kindling (inducción de un foco epileptógeno por estimulación eléctrica repetida de áreas del sistema nervioso central a bajas intensidades) $)^{7-9}$. El kindling supone una estimulación repetida de pulsos eléctricos subconvulsivos. Esta estimulación periódica del cerebro puede producir cambios de manera progresiva si estimulan el sistema límbico ${ }^{10}$. Esta repetida estimulación puede involucrar los procesos de potenciación de larga duración relacionados con los receptores NMDA (N-metil D-Aspartato) ${ }^{11}$.

En resumen, el evento traumático puede provocar cambios bioeléctricos o bioquímicos en el sistema nervioso central, posiblemente dentro del sistema límbico. Esto da como resultado una sensibilización neuronal anormal e incremento de la susceptibilidad (o bajo umbral) a arousal psíquicos y fisiológicos ${ }^{12}$ y trastornos psiquiátricos.

Diferentes estudios basados en la respuesta favorable a la carbamazepina y otros medicamentos antiepilépticos en pacientes con diagnóstico de estrés postraumático, sugieren que la presencia de actividad paroxística en los EEG puede ser explicada por un modelo de kindling o por un trastorno de tipo paroxístico ${ }^{13-14}$. En nuestro caso en particular, es importante destacar que diferentes regiones que forman parte de los lóbulos frontal y temporal integran el sistema límbico, sistema que como hemos hecho referencia, constituye un centro vulnerable a la acción negativa el agente estresante. 
Otro resultado que se destaca en el estudio de esta paciente es la respuesta significativa ante estímulos con valencia desagradable y que representaban situaciones amenazantes a la integridad física de las personas. La respuesta simpática de la piel constituye uno de los índices psicofisiológicos más empleado como correlato de procesos psicológicos, relacionado con la emoción, el arousal y la atención, depende de la activación de las glándulas sudoríparas. Es una medida psicofisiológica que posee un alto nivel de sensibilidad por lo que sus variaciones se consideran evidencias de cambios en el estado cognitivo o emocional del sujeto ${ }^{15}$. Esta respuesta se ha utilizado como indicador de estados de estrés ${ }^{16}$ y como un índice que soporta los hallazgos clínicos en el estudio de diversos trastornos psicofisiológicos relacionados con el estrés ${ }^{15}$.

\section{Conclusiones}

La utilización conjunta de evaluaciones clinimétricas, electrofisiológicas y psicofisiológicas, junto a los métodos convencionales de diagnóstico clínico aplicados a la medicina legal, en el estudio de pacientes donde se sospeche reacción aguda al estrés resulta de extraordinario valor. La detección de las reacciones postraumáticas en fases tempranas hacen posible la identificación de las personas en riesgo de padecer un trastorno por estrés postraumático ulterior que pudieran desencadenar una secuela psíquica con repercusión médico-legal, y por ende permiten el establecimiento de estrategias de intervención profiláctica encaminadas a evitar la cronificación del trastorno ${ }^{15-16}$.

\section{Bibliografía}

1. American Psychiatric Association. Diagnostic and Statistical Manual of Mental Disorder 4 ta ed. Tex rev Washington, DC copyright 2000.

2. Carvajal C, Carbonell CG. Trastorno agudo por estrés: clínica y evolución Rev Chil Neuro-Psiquiat 2002; 40: 195-200.

3. van der Kolk B. Posttraumatic stress disorder and the nature of trauma. Dialogues in Clinical Neuroscience $2000 ; 2: 7-22$

4. Kandel E. Schwartz, J. Jessel T. Essentials of neural science and behavior. Prentice-Hall. 1999.

5. Davidson JRT, Hughes D, Blazer DG. Traumatic experiences in psychiatric patients. J Trauma Stress 1990; 3:459-475.

6. Lang PJ, Bradley MM, Cuthbert BN. International affective picture system (IAPS): technical manual and affective ratings. Gaines-ville, FL: The Center for Research in Psychophysiology, University of Florida. 1995.

7. Adamec R. Transmitter systems involved in neural plasticity under-lying increased anxiety and defense implications for understanding anxiety following traumatic stress. Neurosci Biobehav Rev 1997. 21:755-6.

8. Friedman MJ. Neurobiological sensitization models of posttraumatic stress disorder: their possible relevance to multiple chemical sensitivity syndrome. Toxicol Ind Health 1994; 10:449-62.
9. Grillon C, Southwick SM, Charney DS. The psychobiological basis of posttraumatic stress disorder. Mol Psychiat 1996; 1:278-97.

10. Douglas RM, Goddard GV. Long-term potentiation of the perforant path-granule cell synapse in the rat hippocampus. Brain Res 1975; 86:205-15.

11. van der Kolk BA, The psychobiology of PTSD. J Clin Psychiat 1997; 58(suppl 9):16-24.

12. Stewart JT, Bartucci RJ. Posttraumatic stress disorder and partial complex seizures. Am J Psychiatry 1986; 143:113-4.

13. Lipper S, Davidson JRT, Grady TA, et al. Preliminary study of carbamazepine in Posttraumatic Stress Disorder. Psychosomatics 1986; 27:849-54.

14. Echeburúa E. A tres años del 11-M. Criterios de actuación en el tratamiento psicológico de las víctimas de terrorismo. Papeles del Colegio (Infocop) 2007; $32,24-27$

15. McNally RJ. Psychological debriefing and its alternatives. En S. Begeç (dir.), Theintegration and management of traumatized people after terrorist attacks (pp. 119-131).Amsterdam: IOS Press (Nato Science Series). 2007.

16. Echeburúa y Paz de Corral E. Intervención en crisis en víctimas de sucesos traumáticos: ¿cuándo, cómo y para qué? Psicología Conductual, Vol. 15, № 3 , 2007, pp. 373-387. 